\title{
5. Locating the Beginning and the End in the Triangle
}

\begin{abstract}
In the final chapter, the journey of the character of Jess in the British movie Triangle is the focus. Analysing how Jess is caught within a trance of torturous and tortuous temporalities, this chapter tracks the overarching theme of the circularity inherent in temporality and the possible sifts it continues to create in its movement. Theories of affect are discussed while analyzing Jess's diabolical alternation between being gazed at and counter-gazing.
\end{abstract}

Keywords: Repetition, Circular Temporality, Maternal Love, Mortality and Death

Just the worst time of the year For a journey, and such a long journey: The ways deep and the weather sharp, The very dead of winter. - T.S. Eliot, The Journey of the Magi

The journey is indeed extremely long and arduous, and the timing is always a suspect - any way but this, any time but this, and we could have prevailed.

This chapter will discuss British director Christopher Smith's film Triangle which was first released in the United Kingdom in 2009. The film stars Melissa George as the lead character of Jess. Apart from Jess, the plot involves five main characters - Jess' autistic son Tommy, her friend Greg, his young assistant Victor, Greg's school friend Sally and her husband, Downey. The movie begins with Jess readying to go for a weekend boat trip with her son on Greg's boat named Triangle. She, along with Sally and Downey, has been invited by Greg for this trip. A quick movement of the events, and we see a seemingly-disturbed

Ahlawat. I., Women and Temporality in Literature and Cinema: Negotiating with Timelessness. Amsterdam: Amsterdam University Press DOI 10.5117/9789463729741_CHO5 
Jess arriving at the harbour sans her son who, she claims, is at school (the group apparently expected her to bring him on the trip). Everyone seems to be behaving completely normally except Jess who seems be disturbed and out of place. While at sea, their boat capsizes because the wind drops down on their boat, and a little later, they are swept away by a sea storm.

Except Heather, Sally's single friend, everybody else survives the storm and finds an unclaimed ocean liner, Aeolus. Obviously, they all board it to escape the dangers of the sea. As they walk up and down the ship, it appears deserted and they find, to their horror, that someone has been on a spree to kill them all. While everyone else is killed, Jess manages to escape and then even goes on to throw the masked killer overboard. Just when she is catching her breath, she hears distant cries from the sea and discovers that another version of hers, along with the rest of her co-passengers on Greg's boat, Triangle, is screaming, just like before, for help. Just like before, the group re-boards the Aeolus. Jess soon discovers that she is stuck in a tragic time loop, wherein she is damned to repeatedly witness the trauma of having her boat struck by sea-storm, surviving the waves only to find herself on an abandoned ship and seeing her friends and herself chased by someone on a seemingly-haunted ship.

The movie delves into deep human miseries of living through monotony, the sameness in order to find meaning. It delves into the human need to find the uniqueness in their experience, the human urge to ascribe an exclusive character to their living through events. There lies a pulsating sense of existential authenticity in being assured that one's experience in a particular moment with someone has been unique, unprecedented, irreplaceable and impossible to replicate. Hence, humans invest immense energy and feeling into finding singularity to their existence and going through life. Repetition is commonly seen as an abominable idea - there is no artistic value to it, no idiosyncratic hunger for 'separation'. Repetition is seen as an entrapping idea, devoid of any growth; it is perceived as being tragic and comes with excruciating tribulations.

Living through repetition is lonely. It sets you on a path which is both precarious and certain in its own way - it is sickening and may hurl one towards chaos but it is sure to keep one alive and returning. Jess gets that advantage, as does Dolores, and Eliot's the Sibyl, and Wilde's Sibyl and Molloy's mother. Nietzsche in Thus Spake Zarathustra has seen this as a letting loose of the world and asks of the explorers, '[...] interpret for me the vision of the loneliest one' (2003: 121).

Søren Kierkegaard proclaims at the outset of his text, Repetition and Philosophical Crumbs, '[...] life itself is a repetition' (2009: 3). He draws a 
comparison between repetition and recollection and contends that while recollection is more of a happy, hopeful act, repetition is a courageous willingness. He argues thus,

It requires youthfulness to hope and youthfulness to recollect, but it requires courage to will repetition. He who will only hope is cowardly. He who wants only to recollect is a voluptuary. But he who wills repetition is a man, and the more emphatically he has endeavoured to understand what this means, the deeper he is as a human being. (4)

It can, thus, be convincingly deduced that Jess is a courageous woman. She has the recollections of her son and wants, and hopes, to go back to him, but she also recognizes the tragic plague of her situation. Therefore, she also wills repetition and seeks to perform her karma (action) in all her temporal situations. When the group boards Aeolus, they come across a 1932 photograph of the ship and Sally quells everyone's curiosity about the photograph by acquainting everyone with the myth of the Greek god of winds, Aeolus, the father of Sisyphus who 'made a promise to Death that he didn't keep' (Triangle 2009). This is a presaging of how Jess' venture on the Triangle and then boarding the Aeolus will pan out for her. Her Sisyphean destiny has been established when she too, one may argue, fails to keep her promise, a promise about which we, as audience, find out much later in the film. Towards the end of the film, we see a version of Jess and her son who die in a car accident. But another version of Jess refuses to die and lives on. She takes a car ride to the harbour with a 'driver', who, most likely, is a manifestation of the ride towards the world of death. Jess, instead, asks him to take her to the harbour. When she gets down from the car at the harbour, the driver asks her, 'You will come back, won't you?', to which she replies, 'Yes, I promise'. She does come back but not immediately, and when she does, she is burdened with the curse of Sisyphus.

One may be tempted to ask - 'but, when did it all begin... revolving?', so to speak. The answer may be difficult to locate. One may argue that Downey and Victor noticing the 1932 photograph of the Aeolus is significant and it may be that Jess has been revolving in this temporal loop since then; or one may assert that the group's boat capsized in the Bermuda Triangle area and their taking shelter consequently in the Aeolus resulted in all of them being killed mysteriously, but Jess escapes and is therefore, punished and doomed to eternal repetition.

What is more important, in my opinion, is not to locate the beginning or the end of the Triangle. After all, much like its shape, a triangle is hard to find 
an origin to; every vertex is both the beginning point as well as the ending point. Each edge or line in this triangle is the same in its dimensions - it embodies same spatial and temporal dimensions - and each functions towards sustaining an enthalpic balance within this closed system. What remains important to locate is the passion of this woman, Jess who is caught within the curse of the 'eternal return' and how she continues trying to defeat it. When the movie shows the group boarding the Aeolus for the first time, after surviving the wrecked Triangle, we see them walking around the seemingly-abandoned ship and Downey is heard saying, 'We're just walking for the sake of it'. As viewers of the film, we know that the story belongs to Jess' journey and the other characters are walking for the sake of her journey. Jess, however, is the only one who is walking towards a purpose - however futile but worthy - of getting back to her son.

The movie is a manifestation of what I have called a 'temporal tragedy' in the previous chapter (I carefully coined the term on the lines of a Beckettian 'comic tragedy'). This is to argue that it is equivalent to finding oneself debilitated and disoriented/ dissonanced in a relentless space and time conundrum, and being unable to specify it and define it. Jess is in a similar space and time conundrum, where she is unable to identify the dimensions of her spatial and temporal existence. The time on her watch matches that of the clock on Aeolus; she is the only one among the group whose time has stopped in concurrence with the time on the ship. In a way, she finds a binding with the god of winds, Aeolus. It is noteworthy that it is the wind that precipitates the destruction of their boat, Triangle, as if it is calling out to Jess to move over to its space and time zone. As a matter of fact, when Victor complains of the wind dropping down, Downey explains the situation further and says, 'It's not dropped, it's gone'. As a matter of fact, even the seagulls shown throughout the movie as the guides in Jess' journey have their own significance and seem to blow in the direction carrying the wind. They are like the guiding birds that pull Jess towards an entrapping temporality, but they also implore her to explore paths to freedom. She is also the only one that finds peculiarity in the way she and her group is sucked into the scheme of things of Aeolus, and even warns Greg that she is having a déjà $v u$. Greg, however, dismisses her apprehensions as signs of still being under the trauma of having survived through raging waters, 'Don't you see that this is all just in your mind? Ships don't just magically appear out of nowhere.' A little later, still reeling under tragic confusion, she hears her own voice asking, 'Who are you?'

But, ships do magically appear out of nowhere and suck one into confounding time loops, so much so that one is left befuddled into myriad 
identities from myriad different time zones one has traversed. So, on the one hand, Jess tries to stop the Aeolus in vain, pleading, 'I wanna go home', on the other she valiantly tries to change the sequence of events to induce some disruptive change in order to break out of the temporal loop. The fact that we see so many dead octopuses when a version of hers is washed ashore or so many dead seagulls next to the roadside when the car she and her son are in meets an accident is testament to her refusal to give in to the inexorable force of temporality. In her repetition, she finds the agency for change. Kierkegaard would argue that mere existence brings about no change or movement but only commotion. He further adds, 'Repetition, on the other hand, is transcendence' (2009: 50). Jess is looking precisely for that transcendent aspect in her repetitive existence.

After having gone through these repetitive narratives over and over again, Jess constantly attempts to induce change. In one of these narratives, she is trying to save her friends from the other version of herself who is masked and wants to kill everyone (because this version believes that freedom can be achieved by killing off everyone). She tells a seemingly-suspicious Downey and Sally, 'It's starting over again. That's what's going on... We can change the pattern. Don't you see? We change the pattern, we're not trapped. Then we get off this thing'. This Jess believes that it is in survival that there lies the hope of an escape from the temporal prison. As the other version of hers is simultaneously out on a killing spree, she wants to save the people in her group. As a mortally-wounded Sally, having been attacked by the other Jess, limps towards a corner on the deck, she and the Jess trying to save her are accosted by several dead bodies of Sally that have failed to escape. She consoles Sally, dying in the midst of innumerable other selves of hers, 'I think it will return again. The yacht, the Triangle.... If it does, we'll escape, me and you together. We'll reboard it and escape'. But, it is only Jess' journey and only her choices matter. The others are mere enablers of the choices she makes and the actions she does. They are not fellow travellers but only appendages that may be coldly moulded as per the egoism of Jess' temporal undertakings.

There is also the other Jess, another version of her from another time dimension who has come to believe that freedom will come through killing off everyone, including other versions of herself, Hence, she decides to kill everyone off given that, in her conception, she is not grounded in one single temporality - she is, metonymically, flowing between various temporalities. The masked Jess tells Greg, just before shooting him down, the following:

I don't want you to see my face... Because this is not me. I'm somewhere out there in the yacht and you're with me. And after I kill you, we'll return. 
You see, the boat comes back when you're all dead. I've done everything exactly like before. But when the boat comes back, I'll be ready, I'll be waiting. I'll be on the landing bay, I won't let any of them board, even the other me. I'll make them all stay on the upturned yacht.

Interestingly, this (masked) Jess is never able to bring to fruition this intention, for she is never able to stop the passengers on the returning Triangle from boarding Aeolus. And, this plan of hers is impaired by the other more-recent (non-masked) version of hers who is out to save everybody and eventually overpowers this masked Jess and throws her overboard. A little whirling in the temporal loop will now transform this more-recent (non-masked) Jess into the character of the (masked) Jess; she will come to agree with what an overpowered (masked) Jess would tell her before being thrown overboard, 'They'll return. You have to kill them. It's the only way to get home. It's the only way to save our son'. She gradually becomes the same villain she sought to fight against - it is like finding oneself again amidst the deafening churn of time and timelessness and getting enchanted with one's 'temporal egoism' (my term). It is like giving in to the illusion of belonging to a time and answer its beckoning like it existed truly where it is summoned.

Jess 4 (in the house)

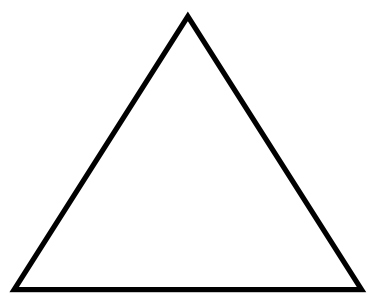

Jess $1 / 2$

(in the yacht Triangle)

Jessi/ 2 (in the Aeolus who is now masked as Jess 3 )

My understanding of how this closed temporal movement transpires is illustrated in the triangle above. Jess 1 and Jess 2 vacillate between the two vertices; Jess 2 becomes Jess 1 when she takes off her jacket to wrap Sally's stomach wound with it (which has been made by the (un)masked Jess 4) and later also proclaims to Victor, 'I know how to get us out of here', and puts on the mask. One of these masked versions is killed by Jess 3 (the most recent version) and thrown into the sea while the other masked version of 
Jess 4 is simply thrown overboard, from where she is washed ashore, and she returns home and sees another version of herself (Jess $1 / 2)$ in the house whom she soon kills. She then takes her place, drives with her son, hits a seagull, finds many more dead seagulls near the road side, meets an accident that kills her son and then she goes to the harbour to catch the new voyage of the Triangle with her group - in the hope of undoing it all this time. She now becomes Jess $1 / 2$. It is when she naps in the Triangle that her amnesia, perhaps self-imposed, takes over and she begins to forget the past cyclical chain of events. Heather would come and wake her up, asking if she is okay, and she would say, 'I had this terrible dream'. When asked more on it by Heather, she would respond that she does not remember, and Heather would tell her that, 'Apparently bad dreams cure you of real life stress'. The fact that Jess does not take even a second to reply that she does not remember her dream, without even trying to ponder over what she dreamt, indicates that she is likely in the know of the past and the incoming future happenings, at least subconsciously.

It is interesting to note here what Gilles Deleuze, in his treatise Difference and Repetition, has said on the concepts of forgetting and remembering, 'It is in repetition and by repetition that Forgetting becomes a positive power while the unconscious becomes a positive and superior unconscious (for example, forgetting as a force is an integral part of the lived experience of eternal return)' (1994: 7-8). In inducing within herself the art of partial or conscious forgetting, Jess finds the strength to survive and go through repetitions with a new vigour and determination. While she does retain the remnants of what she has experienced, and experienced in its entirety, she also makes efforts to paper over her past experiences in order to open the door to hope for the possibility of inducing change to her repeating situation.

Jess is stuck in a tragic temporality that is propped up against her maternal love for her son. Jess tells Greg on the boat Triangle, 'Every day is the same', when he asks her about her son. She adds, 'Tommy likes the things to be a certain way. Yeah. If I do one thing differently, I lose him'. It is this unrelenting, unconditional and timeless love that sets a consequential passion into Jess' temporal journeys. We discussed the concept of 'Reveries' in the last chapter, the idea that people may be induced into a deeper delving into their memories and consciousness through revisiting of certain scenes, events or actions. Jess too is seen experiencing Reveries through her repeated living through temporal loops. We see her dropping her keys every time and the next version always finds them (if one pays attention, it is noteworthy how the keys have also gathered the rust and use of time); we also see her leaving notes for her future self ('Kill everyone'); and we see her dropping her pendant 
in the drain every time. Such repetitive and accumulative actions add to a stream of consciousness which is bound to induce change, even if in a very minimalistic way, into the chain of events in a particular temporal loop.

All versions of Jess experience a déjà vu and even try to convince her group of her experiencing of overlapping temporalities, such that the boundaries between timelines and identities are cruelly blurring for her. She implores Greg to pay attention to this, 'It's just I'm having déjà vu every time I turn a corner'. With Victor, again, the same attempt to familiarize them with her reveries, 'You gotta listen to me. We don't have much time... Downstairs, right now, is a copy of myself. Me, walking and talking with Greg'. It is quite ironical though, for time is all she has!

Marcel Proust conceived of such sudden encounters with the past and rendered the incidence of Reveries beautifully in his own unique conception through his monumental work, Remembrance of Things Past. The 'Combray' section in the novel describes an incident wherein the protagonist recalls how movement in a circuitous route, under the reeling darkness, may make someone feel completely lost and away from home even through one may be right around it (Brezet and Proust 2003: I: 136-160). This is to say that navigating the darkness enough number of times renders one more accustomed to understanding its complexities and fathoming its ever-expanding limits and depths. Wandering around in the darkness is, then, a more convoluted but more existentially authentic and perennial way of living; it is equivalent to being always uncomfortably perched on the edge of time wherein falling into a futurity or regressing into a past is rather seen as a balancing to be sought in order to go home, as it were.

Jess traverses repetitive temporalities and the darkness of recurring memories in her attempt to reveal, discover, resolve and change. There is a forward movement even in her regressions, there is a uniqueness even in her repetitions, for she goes through these tragic time loops with renewed vigour and resolve. Deleuze, in Difference and Repetition, also sees an element of singularity even to a repetitive existence. He contends that 'To repeat is to behave in a certain manner, but in relation to something unique or singular' (1994:1). He argues that repetition is a form of a newness, and that time does not go outside of itself to pass from one phase to another. In other words, even in repetition, the experiencing subject has to synthesize the experiencing of a time, even in loops, anew (71). One can draw an analogy with Jess' situation and contend that Jess is given the privilege of locating fresh threads in her repetitive experiencing of the same events. She is, in terms of Deleuze's arguments, never going back to the same time but is always synthesizing a unique and singular temporality even when repeating 
the same sequence of events. Her experiencing of her tragic moments again and again is as sorrowful every time, if not more, since she also knows there is no end to it. If nothing else, she certainly carries a unique number to the repeating sequence of events - her third journey through the temporal loop, the nineteenth, the one hundred and fiftieth, and so on. It is useful to note what Deleuze explains on experiencing of repetition,

The past is then no longer the immediate past of retention, but also the reflexive past of representation, of reflected and reproduced particularity. Correlatively, the future also ceases to be the immediate future of anticipation in order to become the reflexive future of prediction, the reflected generality of the understanding (the understanding weights the expectation in the imagination in proportion to the number of distinct similar cases observed and recalled). In other words, the active syntheses of memory and understanding are superimposed upon and supported by the passive synthesis of the imagination. (71)

In the context of the above argument, I would like to evoke a scene that happens twice in the movie. The first scene of the film shows Jess hugging her seemingly-terrified son as she emotionally consoles him, 'You're just having a bad dream. That's all baby. That's all it was. Bad dreams make you think you've seen things that you haven't. You know what I do when I have a bad dream? I close my eyes and think of something nice. Like being here with you'. Here, Jess is seen as conceiving her active recall of the past, which arguably has repeated several times, as a subjective anomaly that may be blurred, obliterated and dissociated. At the same time, she is bravely endeavouring to employ a passive synthesis of her imagination for a future to undercut her active recall of a past which is inexorably running towards an unavoidable, unchangeable future. She closes her eyes and thinks of being with her son as both the course as well as the panacea. I further argue that the love for her son is so powerful that it negates her fear of repetition; so much so that she conceives of every new loop, every turn as a particularity, an opportunity. Her Sisyphean emprise is not necessarily quantifiable in time.

Nietzsche has said in Thus Spake Zarathustra that 'Will to love: that is also to be willing to die' (2003: 94). In Triangle, Jess is willingly to die for her son repeatedly because she is willing to reach a time when she would not be separated from her son. In a way, the time vortex that seemingly seeks to confine her and entrap her within circular stories is unable to contain her love and her consciousness of it even in the most traumatic of circumstances. 
In the previous chapter, I argued that Dolores from the television series Westworld was similarly driven by love; her tragedies of seeing her loved ones die made her determined to come back and claim her share of eternity. Dolores and Jess are similar in many ways - they are capable of immeasurable love that transcends time and they are capable of brutal vengeance that carries the advantage of time on its side. In being sent to the same events again and again, they learn to dig deep into the past, comprehend and improvise. On the one hand, they are entrapped within temporality, and on the other, they can never be confined within temporal walls because they are flowing from one time zone to another. This is also to imply that they are neither here nor there. They cannot be registered within a singular temporal syntax and their actions are always open to a future possibility of change, thereby giving no finality to a past (the action) that has occurred already. They are, therefore, timeless - victors over time - and transcend temporal limitations. Jess' and Dolores' existential cornerstone subscribes to one of the central tenets I have posited in all the chapters of this book - the character of being mortal but never dying.

As a matter of fact, Jess' hope lies in precisely this character. She discovers that the yacht, Triangle returns to the same sequence of events when all of the group members have died. She exclaims, 'It returns, when they are dead. It returns, when everyone is dead'. Interestingly, at this point, we also see the ship Aeolus pass by a triangular ice-cliff which, in a way, symbolizes the mountain that Sisyphus was assigned. Jess also, like Nietzsche's Zarathustra, happily accepts her mountain and her punishment, and tries to induce the solace of karma in her seemingly hopeless situation. The movie, it must be noted, begins on an optimistic note of a narrative unfolding and it continues that optimism, despite being weighed down by the grief of repeating the same narrative, until the last scene. We see Jess heading for the harbour - one more of the countless times - hoping to meet another version of hers in the journey (she is, after all, the only one in the group who gets this cruel privilege!). Even if the audience is induced into hopelessness vis- à-vis the narrative in the movie, the protagonist, Jess is optimistic that she will find a way out of this temporal confinement. We are also reminded of the accident scene towards the end when the taxi man in black clothes prods her and tries to convince her, 'No point trying to save the boy. There's nothing anyone can do that's going to bring him back'. Jess, however, refuses to give up. She coldly asks him, 'Who are you?', even though she must have been, at least subconsciously, reminded of him from her past encounters with him. That explains why she so easily chooses to sit in his taxi, with no questions asked from both the sides, and, like the earlier occasions, leaves him waiting at the harbour for her to return. 
As Nietzsche has famously said, 'He who climbs the highest mountain laughs at all tragic plays and tragic realities' (2003: 30); Jess is setting herself up for high mountains and for her, bitter suffering is what will fill her vacuous journeys with a truth that carries potential to redeem her ontological pursuits. Like an artist, she is yearning to create something new out of nauseous monotony. She attempts to break down the sign-object assortment in the time-loop she lives in, and for that, she must create her new woman art - the force of the maternal passion - that could territorialize the space-time that she has been put into. The conception and understanding of this art would render her as the structural centre of 'meaning' in herself, as someone who is able to think and act beyond narrow, limited confines of space and time. This 'meaning' underlines that there is no fixed meaning and that events could be deprived of their authenticity within singular situational temporalities and instead be placed in ambiguous temporalities.

Jess must understand that the lunacy of the current setting is unfolding even as the self-propagating past is quickly warping into the choices that have been generated only just now. She must also understand that consciousness and knowledge are only accessible through the perpetuation of this lunacy. Negotiating the labyrinthine temporalities is as much a self-discovery of one's fragmented existence, one that responds to both suffering and recall. The waters of the sea are symbolic of inviting depths that accept and nurture one, irrespective of one's present worries or past omissions. The waters call out to Jess to dive once more into the temporal whirlwind and explore the undersides of the surfaces of temporalities that, more often than not, are voluminous holes that unravel beneath the rolling waves.

Jess stretches her umbilical cord to reach the time of her son and attempts to remain connected there. There lies the element of completeness, wholeness, that which transcends physical time-space dynamics, and where living time collapses within maternal time. This maternal time is the prescient subconscious that is uncorrupted by external flows of time. Towards the end of the movie, when Jess' car meets a road accident and a version of her dies with her son, Tommy, we see on the death scene a young boy, presumably from the marching band that was rehearsing close to the site, holding a drum with 'AO' written on it. A similar (or same?) drum, with the same initials, is also seen in the party/dining hall of the ship, Aeolus, that the surviving version of Jess boards. One can argue that the maternal time of Jess refuses to give up on her bonding with her son, and continues to exert a semiotic referential force upon all the timelines she travels to. Greg is heard comforting Jess on the Triangle, 'But you can't be everywhere all of the times'. But, she really can. Her resistance to linear time is both 
visceral as well as emotional, and it problematizes the punishing character of her journey within temporal loops. In her own way, she appropriates this Sisyphean punishment in order to grow and conceptualize the apparent abstraction and non-naturalism that she finds her situation enveloped in. This understanding allows her to appreciate the fluidity inherent in time, one that she could not have fathomed if she were to simply live within a limited temporal zone, and this also enables her to stake her individual claims in negotiating the temporal prisons and their abstraction as the implacable stories that just cannot be bound to decay and death.

One could see Jess as being alienated as we progress in the movie. From being with her son and anticipating a happy trip at the sea with her friends to being left all alone, to comprehend, to act and to re-produce her actions and comprehensions, in no particular order, we see Jess as becoming more and more alienated as she continues her journey through time. This implies that she alone has been deemed fit for punishment, although this also possibly implies that she alone has been deemed fit for an eventual redemption. Jess carries an intensity in her actions that nobody else from her group does - she is self-conscious and questioning. She is able to see and in seeing, she is able to activate and satiate her senses into participation. With her continued action/karma, she prolongs the event. This would essentially mean that her resolve to carry on would mean that she avoids a tragic dénouement that awaits the rest of her friends in the group on the boat, Triangle.

Jess is continuously living in temporal loops, but she is not merely inside the loop but is also outside it. In other words, her existence in time is both intensive as well extensive, she is both inside as well as outside. From inside one temporal existence, one Jess is able to see the Jess from another temporal existence. When Jess from another time zone boards Greg's Triangle, she falls asleep and sees another version of her washed ashore with dead octopuses around her. When she boards Aeolus, she sees another version from another time that is masked and on a killing spree. As she enters a room on the ship with Greg, she sees three reflections of herself in three different mirrors (perhaps indicative of the fact that at any given point, there are three versions of Jess existing simultaneously?). When she survives the time on Aeolus and reaches back to her son at home (now), she sees another version of herself from another time already with her son. When her car meets an accident and her son also dies in it, she again sees another version of herself lying dead on the road. This is voyeurism turning in upon itself, but in a fashion that is empowering and not crippling. This is like revisiting her humaneness over and over again and finding a pulsating greed to survive every time. The other Jess becomes a referent for the seeing Jess of a primal desire to continue, to propagate. 
Furthermore, one can contend that in all time zones she functions in, Jess serves to induce both differentiation as well as replication; she is not one but too many, looking at one-another, even though Jess is looking essentially at Jess. In my book, The Gaze of the Caged Woman, I have asserted how such a woman could be seen as having become 'the narcissistic subject of her own gaze' that looks at the mirror, the apparition between time-zones 'only to be seen as oneself to oneself and a queer identification with one's own reflection as a novel manifestation of subject-object alliance' (2018:18). The version being seen is inflective and splintered between a displaced past and the choices it made. Each version of Jess offers an open-ended narration of her story and its temporal coherence even while repeating itself in time loops, such that the choices it made, or must have made, also fall as reveries on the eyes of the seeing Jess.

Jess' specularity traverses several temporal and spatial dimensions; she is here and she is there. Jess is the centre of the universe and Jess is the voyeur; she places herself at the centre and she watches herself from the periphery. She is in an extraordinarily unique position, and is empowered through this play of representation of the self across temporalities as she is also able to peruse through this representation from a distance from another temporality. I further argue that this is a self-involved, almost narcissistic furthering of the self by Jess, a trait that goes on to become self-sustaining and that fosters her pursuit to transcend her repetitive existence to unite with her son in a timeless zone of maternal semiosis. She is dispersed across several time zones and this allows her to collect her subjectivity from several events and spaces. She gets access to herself, her body and her mind in the several time zones she lives in, and this allows her unlimited time and opportunities to develop a distinct understanding of every distinct position she lands in. Therefore, it may be understood that Jess gradually comes to appropriate her tragic existence into one that may help her reorient her sense of alienation onto an alternative temporal landscape wherein she gets to meet versions of herself attempting to prevail over the profundity of the temporal abysses that call out to her. Jess experiences what I have called 'the excesses of selfhood accompanied with the distant perceptual and often even mnemonical apprehension of the externalities, mostly the domain of the Symbolic' (2018: 53).

There is being created in Jess' existence a visual disorder that she is challenged to comprehend outside the fixities of singular truths and linear teleologies. She exists and operates within a cataclysmic liaison of love and death, and therefore, she is challenged to accept the perennial fluidity and changeability in both. The spectator is transformed into a spectacle after 
another cycle of traversing a temporal loop, and the spectator who has now become the spectacle must wait for a while before she becomes the spectator once again. This is an approximation of the spectacular instability yet existential stability that Jess is in possession of. The flowing waters of the sea around her can be appropriately seen as a metaphorical representation of this perennial yet persistent and ever-returning quality of existence.

The spectacle and the spectator are constantly revolving in a temporal vortex. As the first Jess survives the assault of the masked killer, she becomes the spectator of the second Jess who is the spectacle. Some time later, the second (or the first) Jess becomes the spectator while the new third Jess (who just boards the Aeolus) becomes the spectacle; and this continues to go on. Every time a spectator Jess watches a spectacle Jess, she is bound within a repetitive temporal vortex, but even in this repetition, the spectator Jess sees a unique, singular spectacle - a spectacle that not only disheartens the watching Jess because of its relative past's choices but also brims her with hope for a relative future's ability to change; 'We can change the pattern, we're not trapped. Then we get off this thing', as Jess would say, fully convinced with her belief and its unique eventual singularity. On the lines of Deleuze's views on repetition and the singularity inherent in it, one can assert how the spectacle carries an element of singularity even though the spectacle has been occurring in repeated loops. Deleuze states that 'Repetition as a conduct and as a point of view concerns non-exchangeable and non-substitutable singularities' (1994: 1). Jess, almost in a narcissistic obsession with her temporal scope and breadth as a being, comes to gaze at her other selves as the opening up to a revelatory panacea to her sense of tragic entrapment. Her repetition within the specular economy of the temporal loops she lives in and returns to is to also to put into motion the potent instantaneity of gazing deep and gazing long at a past and a future that is non-substitutable (to borrow Deleuze's words) and that grants the spectacle a unique subjectivity and vision of her own.

Towards the middle of the film, Jess is shown as having realized her entrapment within a repeating circle of events and she decides to change and undo the unfolding of events by inducing aberrations in the set narrative. There also comes a scene here when she is confronted with her more recent self and it is interesting to note how the dynamics of spectacle and the spectator come to an extremely blurred zone of perception and apprehension. As the past Jess points a gun at the more recent Jess, she is unable to shoot her, likely because of the fact that she is unable to come to terms with the more recent Jess as being only a spectacle to her that is different and singular in its eventuality. She tries hard to convince her other friends to believe 
her story of repetition; Victor who is another spectator to this meeting of one version of Jess with another is unable to get involved, comprehend or act in this journey that seems to be designed and perpetuated for Jess. Furthermore, as argued in The Gaze of the Caged Woman, it is important to both distance as well as find spaces and times of merger of her many selves; that is to say that 'her apprehension and communication with others is grounded on her communication with and comprehension of her own self' (2018: 67). Inducing aberrations in the set narrative is premised upon her ability to understand it and her larger role in it, and, at the same time, reject it as the finality.

The tyranny of being subject to tragic repetitions is also a gateway to accustoming Jess to temporal incoherencies and their sustaining paradoxes. As Deleuze would argue, 'In every respect, repetition is a transgression. It puts law into question, it denounces its nominal or general character in favour of a more profound and artistic reality (1994: 3). This also counters the common understanding on repetition being not artistic and being banal to the point of being undesired. On the lines of these thoughts by Deleuze, I argue that Jess is similarly engaging in transgression and artistic intrigue by traversing temporal barriers; in her repetition, she carries the vitality of art. One can, thus, further suggest that Jess gets to overcome one time after another time owing to her growing understanding of the warped nature of temporality and its passage, the understanding that temporality is not unidirectional and that a forward movement or a backward movement do not necessarily mean anything except in relational and subjective terms.

Jess' presence in several time zones at once is a caprice at self-discovery that is not directed at reconciling the multiple routes the self takes at different times and different places but is aimed at reinscribing oneself, over these different times and different places, as the point of convergence between a beguiling self of a future Jess who re-examines everything in a familiar set-up and an incommensurate performance of time and its temporality in the entangled irreducibility of motherly love. I contend, furthermore, that watching one self of hers mothering is also a form of self-discovery every time Jess goes through that event. After having been washed ashore, a version of Jess reaches back to her home where she discovers another version of hers with her son and apparently annoyed at him. She is shown gazing at this other self from a window and finds the presence of an alternative force of motherhood in the form of another Jess too incongruent to her desire to escape with her son from the temporal cage that she feels she is entrapped into; not to mention her sense of shock and awe at the aggression she sees in the other self she gazes at. As the Jess in the house hits her son for being 
irresponsible, the Jess from the past/future rings the doorbell to find entry into the spatio-temporal presence the Jess in the house inhabits. As the Jess in the house gazes at her reflection in the mirror in her bedroom, her mirror suddenly presents to her an additional version of her who has been gazing at her and wishes to exclude her from the ever-multiplying versions of her and the ever-challenging, ever-intriguing narrative unfolding in temporal loops.

A little later, this version of Jess would be seen gazing at the dead body of another Jess and feeling relieved to be alive so she can go back to the harbour, board the Triangle, brave the sea-storm, board the Aeolus and survive the ongoing massacre on the ship in order to be washed back to her life in the city where she can, this time, save herself and her son and escape from the curse of repetition and intense suffering. The fact that Jess travels through various time loops, becomes various selves of her own personality - both watching as one version and being watched in another - is indicative of her developing consciousness of this process of being watched and watching being extremely fluid and transient. She develops, in the course of (an unspecified, and unquantifiable) time, a sight that transcends time and its corrosive traits. Being both the audience as well as the actor renders her capable of being in different places at the same time and at different times in the same place. From all these places and all these times, she only thinks of her subjective predicament and her overwhelming desire to escape this feeling of entrapment. The solitude of being with herself and watching from afar herself getting punished and bearing torture - mentally as well as physically - transforms her as a person. The pernicious binding of one's own self watching its other self and also watching itself being watched equips her with a special kind of perception, apprehension and comprehension, one that is forever getting displaced and forming new covalence between an event and a possibility.

In such a context, it is good to quote what Gilles Deleuze, in Difference and Repetition, says 'Infinite comprehension thus makes possible remembering and recognition, memory and self-consciousness (even when these two faculties are not themselves infinite)' (1994: 11). I argue that Jess follows in the film a journey towards such an infinite comprehension through her climbing back and forth in time in order to understand the travails of memory and develop a consciousness in the midst of temporal and semantic mayhem. She must come to terms with her suffering and renounce closure to her temporal loops in order to escape permanent death.

It is interesting to voice Nietzsche's views from Thus Spake Zarathustra here, 'Creation - that is the great salvation from suffering and the lightener of life. But that the creator may come to life, suffering itself is required, 
and much transformation. Yes, much bitter dying must be in your life, you creators!' (2003: 64). Jess has to suffer the trauma of alienation and pursuit of meaning in temporal ambiguity, unlike the rest of her group members, because she is deemed not the victim but the target of a cruel punishment. But this punishment may be relooked at and modulated by the sufferer and turned into an opportunity to wilfully descend into timelessness and formlessness to find new pathways opening up at the cues of her fragmented memories.

I conclude this chapter by voicing Jess' thoughts with the conclusion of Eliot's poem:

All this was a long time ago, I remember,

And I would do it again, but set down

This set down

This: were we led all that way for

Birth or Death? There was a Birth, certainly

We had evidence and no doubt. I had seen birth and death,

But had thought they were different; this Birth was

Hard and bitter agony for us, like Death, our death.

We returned to our places, these Kingdoms,

But no longer at ease here, in the old dispensation,

With an alien people clutching their gods.

I should be glad of another death.

- T.S. Eliot, The Journey of Magi

\section{References}

Ahlawat, Ila. 2018. The Gaze of the Caged Woman. Oxford: Peter Lang.

Deleuze, Gilles. 1994. Difference and Repetition (trans. Paul Patton). New York: Columbia University Press.

Kierkegaard, Søren. 2009. Repetition and Philosophical Crumbs (trans. M.G. Piety). New York: Oxford University Press.

Nietzsche, Friedrich. 2003. Thus Spake Zarathustra (trans. Thomas Wayne). New York: Algora.

Stanislas, Brézet, and Proust, Marcel. 2003. Remembrance of Things Past. New York: NBM Comicslit.

Triangle - British Australian Film https://en.wikipedia.org/wiki/Triangle_(BritishAustralian_film). (retrieved 11 November, 2019).

Triangle, 2009. 
